\title{
Fungi are not all "fun-guys" after all
}

\author{
Maurizio Del Poeta* \\ Departments of Biochemistry and Molecular Biology, Microbiology and Immunology, and Craniofacial Biology, and Division of Infectious Diseases, Medical University of \\ South Carolina, Charleston, SC, USA \\ *Correspondence: delpoeta@musc.edu
}

The evolution of human history has greatly influenced human infectious diseases. For instance, the emergence of industrialization and the human population increase and conglomeration both directly contribute to the spread of microbes. Although the progress of medicine has helped to control infectious diseases, at the same time the advent of certain medical practices has actually favored the occurrence of microbial infections. For instance, the use of antibiotics and corticosteroids removed bacteria as competitors and promoted the development of fungal infections. Certain medical devices, such as catheters, provide the port of entry to bacteria and yeasts colonizing the skin and mucosa. As a result, Candida is the fourth most common hospital acquired sepsis (Perlroth and Choi, 2007; Guery et al., 2009; Rueping et al., 2009), and infection with mold Aspergillus spp. is increasing in patients with hematological malignancies (Munoz et al., 2008; Ruping et al., 2008). The CDC estimates that more than 1 million new cases per year of cryptococcosis will occur worldwide in patients with AIDS, and more than half of those affected will die from the infection. This would mean that cryptococcosis-induced deaths are more frequent than deaths caused by tuberculosis (Harrison, 2009; Park et al., 2009), a drastic increase considering that prior to the mid-1950s, fewer than 300 cryptococcosis cases had been reported in the medical literature (reviewed in Casadevall and Perfect, 1998). Most alarmingly, during the last few years certain Cryptococcus spp. were reported to cause life-threatening infections in immuno-competent individuals. The recent epidemic of human cryptococcosis clustered in the central-eastern region of Vancouver Island, Canada (Stephen et al., 2002; Fraser et al., 2003) is now spreading in the Pacific Northwest of the United States (Datta et al., 2009a,b), almost exclusively afflicting immuno-competent subjects. These recent epidemiological data underscore the high potential for and threat of emerging and re-emerging pathogenic fungi to be transmitted in unexpected geographic and clinical settings likely due, at least in part, to present day sophisticated logistics solutions and easy travel around the globe allow for the transmission of microorganisms despite increased security measures and protection efforts. Fungal infections have thus become an important factor of morbidity and mortality, and represent an increasing burden on the medical system.

The fungal-host interaction is the focus of intense investigation by many scientists, particularly biomedical scientists. However, such studies of fungal interactions with their hosts must include considerations about the fungi's interaction with the environment. Pollution, pesticides, and other environmental toxicants affect the air, water, and soil that all humans (and associated microbiota) require for living. Thus, although these toxicants will affect both human and microbial lifestyles, their outcomes will inevitably be different for each organism in any given situation. For humans, acute or/and chronic toxicity will be the ultimate effect, but for the microbial world, an initial toxic effect may kill some microbes, spare others resistant to the poison, but adaptation will ensue and resistance will eventually occur in those that were initially sensitive. Such resistance maybe attributed to the fungi's rapid reproductive rate and unique mating scheme that permits them to adjust quickly to the initially unfavorable environment. A bacterial or fungal organism may reproduce as fast as within $1-2 \mathrm{~h}$ whereas human beings reproduce in 9 months! As a consequence, the damage to the environment will have an amplified negative effect on human health: one in decreasing human immunity and the other in increasing microbial pathogenicity and virulence, which will ultimately generate new pathogenic variants.

Considering the number of current and emerging fungi, it is notable that diseases of animals including humans caused by fungi are rather rare. This maybe mainly due to the fact that most fungi are saprophytic instead of parasitic in that they prefer to derive their nourishment from dead or decaying organic matter. In contrast to the situation with animals, diseases of plants caused by fungi are likely outnumbering those caused by bacteria, which is also evident from the fact that one of the first responses of plants to injury and infection is the launch of antifungal host resistance mechanisms. Likewise and similar to the dominance of animal - bacterial symbioses, the most common mutualism of plants exists with fungi (i.e., ectomycorrhiza and vascular arbuscular mycorrhiza). It is exciting to see that scientists are finally starting to unveil the secret of the symbiotic nature with plants (Breakthrough in plant-fungi interaction, 2010; Eaton et al., 2010).

Our approach to addressing questions about the relationships among fungi, their hosts, and the environment will directly affect our future. Theories have been proposed that fungal spores exterminated dinosaurs subsequent to a dramatic climate change (Casadevall, 2005). Can a similar scenario also occur for the human species?

Thus, although fungi are more commonly known for their helpful roles in fermenting wine, brewing beer, and raising bread, in reality, fungi are not all "funguys" after all. Rather, they are increasingly affecting human health and medical scientists are finally starting to appreciate what mycologists - experts in study of fungi already know and apply in many sectors of society, such as agriculture, aquaculture, horticulture, industry, and medicine (Coelho, 2009).

Frontiers in Mycology aims to publish papers that study the interaction of fungi with the environment and the host. We aim to develop a single platform in which scientists from different fields are learning how to better control the development of hyper-virulent or/and new pathogenic fungal strains and how to increase the host immune response to better control fungal infections and improve human health. 


\section{ACKNOWLEDGMENTS}

This work was supported by Grants AI56168 and AI72142 (to Maurizio Del Poeta) and was conducted in a facility constructed with support from the National Institutes of Health, Grant Number C06 RR015455 from the Extramural Research Facilities Program of the National Center for Research Resources. Dr. Maurizio Del Poeta is a Burroughs Wellcome New Investigator in Pathogenesis of Infectious Diseases.

\section{REFERENCES}

Breakthrough in plant-fungi interaction (2010). Massey University, New Zealand. Available at: http://www. massey.ac.nz/massey/about-massey/news/article. $\mathrm{cfm}$ ? mnarticle =breakthrough-in-plant-fungirelationship-07-07-2010.

Casadevall, A. (2005). Fungal virulence, vertebrate endothermy, and dinosaur extinction: is there a connection? Fungal Genet. Biol. 42, 98-106.

Casadevall, A., and Perfect, J. R. (1998). Cryptococcus Neoformans. Washington, DC: ASM Press, 381-405.

Coelho, S. (2009). Fun with fungi: mycology careers. Sci. Careers, doi: 10.1126/science.caredit.a0900084.

Datta, K., Bartlett, K. H., Baer, R., Byrnes, E., Galanis, E., Heitman, J., Hoang, L., Leslie, M. J., MacDougall, L., Magill, S. S., Morshed, M. G., and Marr, K.A. (2009a). Spread of cryptococcus gattii into Pacific Northwest region of the United States. Emerg. Infect. Dis. 15, 1185-1191.

Datta, K., Bartlett, K. H., and Marr, K. A. (2009b). Cryptococcus gattii: emergence in Western North America: exploitation of a novel ecological niche. Interdiscip. Perspect. Infect. Dis. 2009, 176532.

Eaton, C., Cox, M., Ambrose, B., Becker, M., Hesse, U., Schardl, C., and Scott, B. (2010). Disruption of signaling in a fungal-grass symbiosis leads to pathogenesis. Plant Physiol. 153, 1780-1794.

Fraser, J. A., Subaran, R. L., Nichols, C. B., and Heitman, J. (2003). Recapitulation of the sexual cycle of the primary fungal pathogen Cryptococcus neoformans var. gattii: implications for an outbreak on Vancouver Island, Canada. Eukaryot Cell 2, 1036-1045.

Guery, B. P., Arendrup, M. C., Auzinger, G., Azoulay, E., Borges Sa, M., Johnson, E. M., Muller E., Putensen, C., Rotstein, C., Sganga, G., Venditti, M., Zaragoza Crespo, R., and Kullberg, B. J. (2009). Management of invasive candidiasis and candidemia in adult non-neutropenic intensive care unit patients: Part I. Epidemiology and diagnosis. Intensive Care Med. $35,55-62$.

Harrison, T. S. (2009). The burden of HIV-associated cryptococcal disease. AIDS 23, 531-532.

Munoz, P., Guinea, J., Narbona, M. T., and Bouza, E. (2008). Treatment of invasive fungal infections in immunocompromised and transplant patients: AmBiLoad trial and other new data. Int. J. Antimicrob. Agents 32(Suppl. 2) S125-S131.

Park, B. J. Wannemuehler, K. A. Marston, B. J. Govender, N., Pappas, P. G., and Chiller, T.M. (2009). Estimation of the current global burden of cryptococcal meningitis among persons living with HIV/AIDS. AIDS 23, 525-530.

Perlroth, J., and Choi, B. (2007). Spellberg, nosocomial fungal infections: epidemiology, diagnosis, and treatment. Med. Mycol. 45, 321-346.

Rueping, M. J., Vehreschild, J. J., and Cornely, O. A. (2009). Invasive candidiasis and candidemia: from current opinions to future perspectives. Expert Opin. Investig. Drugs 18, 735-748.

Ruping, M. J., Vehreschild, J. J., and Cornely, O. A. (2008). Patients at high risk of invasive fungal infections: when and how to treat. Drugs 68, 1941-1962.

Stephen, C., Lester, S., Black, W., Fyfe, M., and Raverty, S. (2002). Multispecies outbreak of cryptococcosis on southern Vancouver Island, British Columbia. Can. Vet. J. 43, 792-794.

Received: 03 August 2010; accepted: 06 August 2010; published online: 27 August 2010.

Citation: Del Poeta M (2010) Fungi are not all "funguys" after all. Front. Microbio. 1:105. doi: 10.3389/ fmicb.2010.00105

This article was submitted to Frontiers in Fungi and Their Interactions, a specialty of Frontiers in Microbiology.

Copyright (c) 2010 Del Poeta. This is an open-access article subject to an exclusive license agreement between the authors and the Frontiers Research Foundation, which permits unrestricted use, distribution, and reproduction in any medium, provided the original authors and source are credited. 